\title{
El currículum universitario como proyecto político para una mayor justicia entre saberes
}

\author{
Norma Di Franco \\ Graciela Di Franco \\ Silvia Siderac ${ }^{1}$
}

\section{RESUMEN}

La presentación se enmarca en la formación universitaria de profesorado, en el trabajo desarrollado en la cátedra Currículum, /Práctica Curricular en la que se discuten los mandatos, las prescripciones oficiales, los intersticios, la construcción y la distribución de los saberes que las sociedades declaran sustanciales en las ciudadanías de cada época. El gran objetivo es la descolonización del currículum, preguntarnos qué entendemos por conocimiento válido, quién lo construye y cómo lo hace, con qué medios y objetivos se presenta como válido, quién lo distribuye y cómo. La presentación permite configurar nuestra síntesis del currículum universitario como proyecto político: el marco de fundamentos y de acción a partir de las referencias de las Epistemologías del Sur, los desafíos de una ecología de saberes, los cuestionamientos metodológicos, las alternativas no extractivistas, los referenciales legales para el desarrollo de prácticas informadas, la importancia actual de una Educación Sexual Integral, las producciones de los/as estudiantes y las intervenciones en una propuesta educativa político-curricular.

Se habilitan instancias de diseño de materiales alternativos elaborados por las/ os estudiantes de los profesorados en sus prácticas. En este trabajo compartimos lo que hemos construido como nuestro espacio de acción: las prácticas curriculares en la formación de profesorado.

1 Las tres autoras pertenecen al Instituto de Ciencias de la Educación para la Investigación Interdisciplinaria, Facultad de Ciencias Humanas, Universidad Nacional de La Pampa. Mail de contacto: iceii@humanas.unlpam.edu.ar 
Se adjuntan producciones de las/os estudiantes de los profesorados, en las que ponen en juego los fundamentos debatidos y las experiencias desarrolladas en las aulas.

Palabras clave: Prácticas de formación de profesorado, currículum universitario, descolonización del currículum. 


\begin{abstract}
This presentation is part of the university teacher training programme, in the work carried out in the Curriculum Chair, in which we discuss mandates, official prescriptions, interstices, the construction and distribution of knowledge that societies declare substantial for the citizenships of each era. The main objective is the decolonization of the curriculum, to ask ourselves what we understand by valid knowledge, who builds it and how it is done $t$, with what means and objectives it is presented as valid, who distributes it and how. This presentation allows us to configure our synthesis of the university curriculum as a political project: the framework of foundations and action based on the references of the Epistemologies of the South, the challenges of an ecology of knowledge, the methodological questions, the non-extractivist alternatives, the legal references for the development of informed practices, the current importance of a Comprehensive Sexual Education, the students' productions and interventions in a political-curricular educational proposal.
\end{abstract}

Keywords: Teacher education practices; university curriculum; decolonization of the curriculum.

Fecha de recepción: 03/11/2019

Fecha de aceptación: 02/06/2020 


\section{El currículum universitario como proyecto político para una mayor justicia entre saberes}

\section{INTRODUCCIÓN}

La presentación se enmarca en la formación universitaria de profesorado, en el trabajo que desarrollamos año a año en una cátedra denominada Currículum/Práctica Curricular, en la que cursan estudiantes de profesorados de diferentes facultades y carreras (matemática, física, química, biología, inglés, computación), y en la que se discuten los mandatos, las prescripciones oficiales, los intersticios, los debates en la construcción y la distribución de los saberes que las sociedades declaran sustanciales en las ciudadanías de cada época.

Nos preguntamos ¿Cuáles son los saberes necesarios en esas prácticas educativas? ¿Cómo pensar esos saberes buscando construir autonomía de pensamiento y de acción? El centro de la asignatura se posiciona a partir de pensar la educación como acto político en tanto favorece la construcción de sujetos que puedan comprender el mundo e intervenir en él. Para ello, todos los contenidos y actividades se articulan para analizar y valorar a la escuela como espacio de poder de práctica informada y volver la mirada sobre los espacios de formación. Esto nos compromete activamente y deja en evidencia nuestra manera de pensar políticamente.

En ese contexto, el gran objetivo de la asignatura es la descolonización del Currículum. Este se desagrega en generar oportunidades para que las/os estudiantes puedan analizar la práctica curricular desde fundamentos políticos, sociohistóricos y culturales en el contexto de América Latina; indagar sobre las relaciones entre estado y escolarización, conocimiento y saber, poder y dominación en sociedades democráticas; interpretar el currículum real como espacio de comprensión e intervención en las tareas de enseñar y de aprender; analizar las políticas culturales que regulan los libros de texto y las nuevas tecnologías; intervenir en una praxis curricular que articule la conflictiva, desigual y abismal relación entre teoría y práctica; desarrollar estrategias que incorporen al currículum perspectivas orientadas a producir el quiebre y la desestabilización del sentido común y las naturalizaciones sostenidas desde las imposiciones hegemónicas.

Nos proponemos en este artículo hacer una reconstrucción crítica de la experiencia formativa en el nivel superior. Para ello compartimos lo que hemos construido como nuestro espacio de acción, las prácticas curriculares en la formación de profesorado.

\section{ANTECEDENTES. EL CURRÍCULUM UNIVERSITARIO COMO PROYECTO POLÍTICO.}

Partimos de entender que una currícula universitaria es un proyecto político institucional. Lo que Alicia de Alba (1998) define como:

(...) la síntesis de elementos culturales (conocimientos, valores, costumbres, creencias, hábitos) que conforman una propuesta político - educativa pensada e impulsada por diversos grupos y sectores sociales cuyos intereses son diversos y contradictorios, aunque 
algunos tiendan a ser dominantes o hegemónicos, y otros tiendan a oponerse y resistirse a tal dominación o hegemonía. Síntesis a la cual se arriba a través de diversos mecanismos de negociación e imposición social. (pp. 59)

Es un proyecto político que analizamos a la luz de dos relaciones fundantes: la relación entre sociedad y educación y la relación de nuestras teorías y nuestras prácticas. De allí la fundamental función del sistema educativo en tanto que es un bien público que asegura la construcción de saberes. Esto no sólo sucede hoy, sino que seguirá ocurriendo, dado que brinda el conocimiento organizado que las sociedades expresan necesitar y fundamentalmente, porque educar es una tarea moral, que compromete a quien la realiza, es una práctica humana, social, política e históricamente situada que busca la construcción de la ciudadanía en democracia. Esto requiere de una justicia distributiva que trabaje por todas/os las/os ciudadanas/os. En este sentido, la igualdad individual es la condición de un orden social justo, no su objetivo.

Esta democracia debe trabajar a favor de una justicia curricular (Torres Santomé, 2011) pensada como el resultado de analizar el currículo que se diseña, pone en acción, evalúa e investiga tomando en consideración las necesidades y urgencias de todos los colectivos sociales; en un proyecto más amplio de intervención sociopolítica destinada a construir un mundo más humano, justo y democrático.

Ahora bien, las escuelas democráticas (Apple y Beanne, 2000) no se producen por causalidad, se derivan de intentos explícitos de las/os educadores de crear estructuras y procesos democráticos mediante los cuales se configure la vida en la escuela y de organizar un currículum democrático que aporte experiencias democráticas a las/ os jóvenes. Debemos revisar la relación entre el conocimiento y su distribución, lo que implica replantear el rol docente desde una formación crítica que pueda trabajar a favor de la defensa de los tres principios de la justicia curricular: los intereses de los menos favorecidos, la participación y la escolarización común y la producción histórica de la igualdad (Connell, 1997).

Jurjo Torres Santomé (1997), en su análisis del mundo observado desde las instituciones escolares para pensar en la lucha contra la exclusión, señala que, la escuela -como cualquier otra institución social- debe ser entendida en relación a la situación y tiempo en que se desarrolla dado que se planifican al servicio de los intereses de esos contextos. De ese modo ubica a los centros escolares en el entretejido de relaciones del neoliberalismo e identifica las realidades marginadas en las escuelas, en las aulas, en el saber de los diseños curriculares y de los libros de texto:

En el trabajo escolar contra la exclusión y el racismo es imprescindible detenerse a analizar la cultura, los contenidos culturales con los que se trabaja en las aulas. (...) Las informaciones visibles tratan de justificar el porqué del éxito de los colectivos y personalidades de los grupos hegemónicos; y además también cuentan con el subterfugio de numerosos implícitos que coadyuvan en la desvalorización de las culturas distintas y/o rivales y, por supuesto, de las marginadas. (pp. 7)

Es así que analiza las dificultades en el trabajo escolar antirracista para pensar y llevar delante un curriculum antimarginación.

Nos preguntamos -a los modos de Santos (2010)- por qué el pensamiento emancipador de larga tradición en la cultura occidental, no ha emancipado en la 
práctica a la sociedad. Señala el autor, en este sentido, que la opresión y la exclusión tienen dimensiones que el pensamiento crítico emancipatorio de raíz eurocéntrico occidental ignoró. Una de esas dimensiones fundamentales es la epistemológica en tanto reconocer qué se considera conocimiento válido, quién lo construye, cómo lo hace, quién y cómo se distribuye. De este modo no se busca desconocer la teoría crítica occidental, sino ponerla en tensión cuestionando capitalismo y colonialismo para poder analizar problemas sociales, políticos y curriculares propios de nuestro tiempo en Latinoamérica. Es fundamental entonces, descolonizar el currículum.

Estos son los argumentos que se abordan en el primer eje de la asignatura, generando preguntas acerca de la mudanza del sentido histórico del currículum centrado en el control al reconocimiento de unos saberes en una pedagogía del cuidado.

En el eje dos se analizan currículum, textos, prácticas, en tanto mediadores culturales y podemos advertir que hay quienes permanecen "de aquel lado de la línea" y "los de este lado de la línea" (Santos, 2010) y cómo los de este lado finalmente pierden definición, se vuelven invisibles. Presenta el autor distintos modos de producir ausencias desde una racionalidad monocultural: el ignorante, el retrasado, el inferior, el local/particular, el improductivo o estéril. Cada una de estas monoculturas colabora en la construcción de subjetividades que se alejan de la resistencia y las transformaciones. La posibilidad la ofrece el autor desde la emergencia, de la ecología de saberes, temporalidades, reconocimiento, de las transescala y de las productividades.

En el tercer eje nos preguntamos acerca de la relación entre estructura y acción que exprese la necesidad de construcción de una praxis que plantee dialéctica, conflictiva y productivamente la relación teoría y práctica. “Para una teoría ciega, la práctica social es invisible; para una práctica ciega, la teoría social es irrelevante" (Santos, 2006: 16).

El cuarto eje analiza el rol de las/os profesores en el diseño de un currículum democrático. Esto obliga a definir que el proyecto político hacia donde se encaminan estos saberes se constituye en la interculturalidad crítica, generando posibilidades de investigación y producción alternativas al currículum editado, reflexión sobre las propias ideas y práctica del currículum vivido, cultura colaborativa.

Estamos convencidas que

(...) no hay práctica social más política que la práctica educativa (...) En efecto la educación puede ocultar la realidad de dominación y alienación, o puede, por el contrario, denunciarlas, anunciar otros caminos, convirtiéndose así en una herramienta emancipatoria (Freire, 2003:74).

El quinto eje recupera la pregunta de Tadeu da Silva (1997) ¿Cómo desmasculinizar el currículo?, ¿cómo desoficializarlo?, ¿cómo desfetichizarlo? En suma, ¿cómo descolonizarlo? Los derechos humanos se constituyen en el horizonte de comprensión e intervención docentes a favor de los derechos interculturales al conocimiento, al reconocimiento, a la incorporación de derechos no reconocidos aún al servicio de un currículum crítico, integrado, decolonial. El análisis de estos cinco ejes pone en diálogo la formación en el aula universitaria y en un aula de escuela secundaria donde las/os estudiantes se desempeñan como ayudantes. Estas ayudantías territorializan la formación, la vuelven prácticas curriculares cercanas, arriesgadas, impredecibles, 
valiosas, inquietantes, desafiantes, desestructurantes, interpeladoras de habitus y sentidos teóricos. Todas notas que fundamentan un profundo sentido profesional en las antípodas de las argumentaciones técnicas, normativas, aplicacionistas

La situación problemática que pone en marcha esta indagación situada es cómo construir saberes y conocimientos desde la currícula universitaria que recuperen esas voces ausentes en las prescripciones - que se sostienen en perspectivas naturalizadas patriarcales, racistas, coloniales- a favor de una interculturalidad crítica.

Para hacer una reconstrucción crítica de la experiencia formativa en el nivel superior queremos describir: por un lado, la estructura semántica en una síntesis relacional de los ejes a partir de los cuales se configura y se organiza la asignatura Curriculum/ Práctica Curricular. Por el otro, los dispositivos que se van entrelazando y que marcan la trama de una metodología de trabajo que articula prácticas de formación en la universidad y prácticas contextualizadas de ayudantías docentes en los colegios.

\section{MARCO DE FUNDAMENTOS Y DE ACCIÓN A PARTIR DE LAS REFERENCIAS DE LAS EPISTEMOLOGÍAS DEL SUR. DESAFÍOS PARA UNAS PRÁCTICAS CURRICULARES POR UNA ECOLOGÍA DE SABERES}

El desafío inmediato está en poder desarrollar un marco de fundamentos y de acción a partir de las referencias de las Epistemologías del Sur, que se constituya en nuestro nuevo marco teórico, actualizado, informado y ampliado, intérprete de las necesidades de un currículum de los profesorados con miras a la descolonización.

En este sentido, nos resultan sustanciales los aportes de Santos (2009, 2010, 2018) al analizar que la opresión y la exclusión tienen dimensiones que el pensamiento crítico de raíz eurocéntrico occidental ha ignorado. Una de ellas es la dimensión epistemológica, y -central a nuestro trabajo-, que “(n)o es posible una justicia global sin una justicia cognitiva global" (2009, p. 179). Se vuelve crucial en ese análisis y en nuestras preocupaciones acerca de los saberes y el currículum, preguntarnos qué entendemos por conocimiento válido, quién lo construye y cómo lo hace, con qué medios y objetivos se presenta como válido, quién lo distribuye y cómo.

Desde este planteo se advierte que la comprensión del mundo es "mucho más amplia y variada de lo que la tradición científica o filosófica occidental considera importante" (Santos, 2009, p. 99). La epistemología es toda concepción, reflejada o no, sobre las condiciones que vuelven válido un conocimiento. Para combatir el desperdicio de experiencia, no es suficiente proponer otro tipo de ciencia, urge construir una nueva postura epistemológica.

Recuperamos de María Paula Meneses y Karina Bidaseca (2018):

As epistemologias do Sul dizem respeito à produção e validação de conhecimentos ancorados nas experiências de resistência [e luta] dos grupos sociais que têm experimentado injustiças, opressões e destruições sistemáticas praticadas pelo capitalismo, colonialismo e patriarcado.(...) Neste contexto, a ciência moderna é, também, parte das Epistemologias Do Sul, na medida em que consegue dialogar, de forma tendencialmente horizontal, com outros conhecimentos, socialmente legítimos, promovendo uma 
ecologia de saberes. Mas, tal como os outros saberes, não detém o estatuto de único saber válido. (pp.13)²

Santos manifiesta que las diferencias han sido desperdiciadas en la invisibilización de la naturalización y propone trabajar una Sociología de las Ausencias. En su expresión, mucho de lo que no existe en nuestras sociedades es producido activamente como no existente, saberes suprimidos, silenciados, marginados, no creíbles, descartables, invisibles a la realidad hegemónica del mundo, reduciendo la realidad a lo que en esos términos existe. Así, se contrae el presente disminuyendo su riqueza y dejando fuera muchas voces, muchas vidas, muchas/os otras/os.

La inquietud entonces, se traduce en la necesidad de reflexionar acerca de qué es producido como no existente en materiales curriculares de las disciplinas. "La colonialidad del conocimiento (como la del poder) sigue siendo fundamentalmente instrumental para expandir y reforzar las opresiones causadas por el capitalismo, el colonialismo y el patriarcado." (Santos, 2018, p. 315).

Para el autor hay cinco lógicas de producción de no existencia en esta realidad hegemónica impuesta:

La monocultura del conocimiento válido: que sostiene que el único saber riguroso es el científico. Es la monocultura de la ciencia occidental que genera el epistemicidio de conocimientos alternativos dejando fuera a pueblos o grupos sociales que tengan prácticas construidas desde esos saberes. Podemos analizar estas ausencias en las propuestas editoriales y materiales curriculares cuando no hay referencias de nuestros pueblos indígenas, de sus prácticas de salud, de alimentación, de problemáticas y debates que son hoy agenda de los grupos activistas o de militancia feminista como pueden ser los feminicidios, el abolicionismo, la interrupción voluntaria del embarazo.

La monocultura del tiempo lineal: es la idea respecto de que la historia tiene una dirección y desarrollo en donde los países desarrollados van delante y son, por tanto, más progresistas que los subdesarrollados; las instituciones y maneras de estar en el mundo marcan el camino con las ideas de progreso, modernización, desarrollo -ahora globalización- que deberíamos seguir. La segunda forma de producción de ausencias es, entonces, la residual, pre-moderna, salvaje. Es imposible pensar que los países menos desarrollados puedan tener algún aspecto superador de los países del Norte. Son estos "centros", como ellos mismos se denominan los lugares que escriben cómo será, por ejemplo, la educación en América Latina.

La monocultura de la clasificación social, que se apoya en la naturalización de las diferencias que ocultan jerarquías con relación a la clasificación racial, étnica y sexual. Los inferiores en este marco lo son "por naturaleza". La jerarquía es consecuencia de su diferencia-inferioridad natural. La racionalidad occidental no sabe pensar diferencias con igualdad; las diferencias son siempre desiguales. Lo que no está es

2 Las epistemologías del Sur se refieren a la producción y validación de conocimiento anclado en las experiencias de resistencia [y lucha] de grupos sociales que han experimentado injusticias, opresión y destrucción sistemática practicada por el capitalismo, el colonialismo y el patriarcado. (...) En este contexto, la ciencia Moderna también forma parte de las Epistemologías del Sur, en la medida en que logra dialogar, en formato horizontal, con otros conocimientos, socialmente legítimos, promoviendo una ecología del conocimiento. Pero, al igual que otros conocimientos, no tiene el estado del único conocimiento válido. (2018, p.13) 
porque es inferior y por tanto no deseable, por eso no vamos a encontrar en los libros de texto de nuestras disciplinas ni negros, ni ranqueles, ni transexuales, ni lesbianas, por ejemplo, y sí vamos a encontrar varones y mujeres ocupando las jerarquías que se deberían naturalizar.

La monocultura de la superioridad del universal: racionalidad que propone que siempre hay una escala dominante de las cosas, primero fue el universalismo y hoy es la globalización; consiste en generar ideas o entidades que son "validadas" independientemente del contexto en que ocurran. Se crea de este modo la ausencia de lo genuinamente local. Lo particular y lo local parecen no tener dignidad, no aparecen como creíbles, se vuelven invisibles, desechables, no deseables frente a lo universal, global, hegemónico.

La monocultura de la productividad: que resume todas las referencias en el productivismo capitalista, aplicado tanto al trabajo como a la naturaleza. Esto es bien distinto de las formas organizativas, por ejemplo, de los/as indígenas o de los/as campesinos/as, que incluye los tiempos de la naturaleza y de la recuperación que necesita la tierra o la lógica organizativa de movimientos de colectivos de desocupados/as o de trabajadores/as precarizados/as que se organizan comunitariamente. Así, en esta monocultura, todo lo que no se adecua a la idea de producción capitalista es improductivo, lento, poco rentable, no "convenientes" a la idea de progreso y no aparecen en el currículum real.

Nuestra problemática queda configurada entonces, de miras a la comprensión acerca de cómo operan aquellas racionalidades que, a modo de monoculturas, configuran presencias y producen ausencias; cómo maniobran y cómo se actualizan las lógicas de producción de no existencia - ignorantes, primitivas, inferiores, locales o improductivas-, que organizan y dan sentidos indiscutidos a las prácticas y a los saberes que (no)se enseñan y que (no)se aprenden en las aulas. De allí la trascendencia de revelar la diversidad y multiplicidad y “hacerlas creíbles en contraposición a la credibilidad exclusivista de las prácticas hegemónicas" (Santos, 2009, p. 125).

Los casos identificados en los trabajos con materiales curriculares y editoriales frecuentes en nuestros contextos de enseñanza, referencian el rigor del saber académico expresado en lenguaje técnico, con precisión, en monocromo y sin emociones; el vector del progreso orientado por los países centro cuyos tiempos y su dirección marca la única orientación lineal reconocible; las jerarquías mostradas como consecuencia de inferioridades naturales e inevitables; lo universal, global y hegemónico instalado desde una imposición que sustituye lo local; y la productividad como lógica organizativa que determina estéril e inútil a cualquier otra forma de producción y de trabajo.

Se ofrece un conocimiento descontextualizado, ahistórico, apátrido, sin conflictos, alejado de las/os sujetos y de sus culturas vitales. Esto constituye una propuesta que refuerza dejar a las/os ciudadanas/os sin mecanismos de participación, en un código restringido cuando no inaccesible, sin ninguna posibilidad de inserción en los contextos reales desde donde se construye, con un estado ausente. Esta compleja, sutil, omnipresente cultura social penetra los ritos y costumbres grupales como los intereses, expectativas, rendimientos y formas de comportamiento de todas/os quienes interactúan en la escuela. En este sentido, las alternativas descriptas por las ecologías de saberes, de temporalidades, del reconocimiento, de transescala y de las 
productividades, contribuyen a la construcción de la posibilidad. La identificación de su influencia en nuestras prácticas educativas se vuelve imprescindible para intentar un desarrollo más autónomo en la formación de profesorado, "tendríamos que enseñar democracia desde la perspectiva de los esclavos y de los trabajadores precarizados; tendríamos que enseñar ciudadanía desde la perspectiva de los no ciudadanos." (Santos, 2018, p. 317)

Desde la Sociología de las emergencias se va a producir una enorme cantidad de realidad que no existía antes porque se crean nuevos modos de entender.

En nuestras prácticas docentes las mencionadas, cuestiones curriculares nos implica vitalmente porque:

(...) a descolonização do currículo implica conflito, confronto, negociações e produz algo novo. Ela se insere em outros processos de descolonização maiores e mais profundos, ou seja, do poder e do saber.Nesse processo, a superação da perspectiva eurocêntrica de conhecimento e do mundo torna-se um desafio para a escola, os educadores e as educadoras o currículo e a formação docente. (Gomes, 2012, p. 107, traducción propia) ${ }^{3}$

\section{LAS METODOLOGÍAS}

La indagación interpretativa que fundamenta este trabajo tiene más de artesanía que de arquitectura (Santos, 2009), por lo que buscamos analizar una matriz curricular organizada desde saberes no cuestionados que mantienen invisibilidad sobre sujetos y prácticas. Las herramientas metodológicas de las que nos valemos: a) Partir de las voces de Ixs estudiantes a través de sus concepciones personales, biografías escolares para afinar la escucha desde el contexto y compartir rol del estado, funciones de la escuela pública, rol docente, en síntesis qué ciudadanxs deberíamos formar y cuáles son los conocimientos que esa formación reclama; b) Observación de la participación en las ayudantías y el diseño de un registro de campo durante el tiempo que permanecen en las escuelas y c) Trabajo con registro oficiales y documentos públicos que permite analizar y sistematizar contenido proveniente de fuentes editoriales y legales. El trabajo metodológico fue realizado con dos tipos de documentos: de las editoriales y de la legislación nacional y provincial. Leer de manera cruzada y comparativa los libros de textos con los diseños curriculares y los marcos legales nos ha ayudado para integrar el sentido de los contenidos a enseñar en claves de una currícula crítica y descolonial. De este modo, el estudio de los procesos de construcción y validación de los contenidos, particularmente la presencia o ausencia de determinados saberes, es fundamental en los trayectos formativos que realizan nuestras/os futuros docentes

En ese paraguas, nos resulta una necesidad habilitar instancias de diseño de materiales alternativos elaborados por las/os estudiantes de los profesorados.

Desde el rol de docentes investigadoras, resulta necesario cuestionar metodologías, trabajar en alternativas no extractivistas, usando diferentes lenguajes, discutir

3 (...) la descolonización del currículum implica conflicto, confrontación, negociaciones y produce algo nuevo. Se inserta en otros procesos de descolonización importantes y más profundos, es decir, de poder y conocimiento.En este proceso, superar la perspectiva eurocéntrica del conocimiento y el mundo se convierte en un desafío para las escuelas, educadores y educadores, currículum y formación docente. (Gomes, 2012: 107) 
objetividad y neutralidad. Esto implica también construir diálogos antes que entrevistas, en traducciones interculturales que demandan conocer mucho del campo, y que se convierten en resultados de un colectivo, de un proyecto que beneficie a todas/os, como sujetos, no como objetos de la investigación. Entre las cuestiones que permanecen transparentes en las investigaciones están las que se concentran en los marcos metodológicos y las estrategias que validan aquello que se produce. Las nociones de archivo y de campo necesitan ser discutidas. Es necesario comprender que no existe ninguna exterioridad entre las técnicas de producción del conocimiento científico en la modernidad y las formas imperiales del poder. Si pensamos en las formas en cómo, se legitimó, la conformación del corpus y la manera de hacer el trabajo académico y científico, tiene todas las estrategias imperiales de producción de conocimiento del poder y del propio sujeto del poder (Rufer, 2018).

Desde esta fundamentación, las dimensiones de las -las prácticas curriculares en la formación de profesorado son analizadas para explicitar fuertes relaciones de poder, concepciones hegemónicas e imposiciones oficiales. Constituyen además la posibilidad de entenderlas como espacio de conflictos y lucha por la incorporación de saberes y posiciones no reconocidas, negadas, maltratadas.; Utilizamos para ello los mismos descriptores que dan cuenta de las estrategias y metodologías de trabajo en la universidad y en las aulas:

- los fundamentos: la configuración curricular de nuestros ejes conceptuales como fundamentos de la asignatura y unidades de contenidos para una educación como proyecto político/ la enseñanza como proyecto latinoamericano/ escuelas democráticas/ justicia curricular/ meritocracia/ igualdad de oportunidades e igualdad de posiciones/descolonización del currículum/ currículum de ausencias y de emergencias/ racionalidades curriculares;

- metodologías de desarrollo, hacia una praxis que se juega entre el trabajo en ayudantías en escuelas públicas gratuitas mientras se cursa y se trabaja en aulas de la universidad con categorías conceptuales que se transformen en herramientas analíticas que colaboren y den argumentos en el análisis/ reflexión de las tareas en aula;

- las voces de la exclusión, en diálogos y debates de las/os estudiantes universitarios con sujetos protagonistas de fuertes exclusiones. Citamos algunas: Sonia Sánchez (prostitución, proxenetismo y trata), Susy Shock (crianzas, paternidades, familias hegemónicas en cuestionamiento), Diego Sparza (de la igualdad legal a la igualdad real, diversidad de género), Pilar Galende (salud pública y justicia, debates acerca de la Interrupción Legal del Embarazo), Camilo Blajaquis (el arte vence a la muerte, director de cine después de la cárcel);

- herramientas simbólicas que utilizamos (letras de canciones infantiles, videos de segmentos de actualidad política en nuestro país, películas referentes de posicionamientos educativos, análisis de casos -inmigrantes, xenofobia, trata de personas, discriminación étnica, por modelos de belleza, por religión, acoso callejero, embarazo en la adolescencia, adolescencia trans, barreras de la inclusión escolar, entre otras);

- los marcos legales y las luchas allí presentes/ausentes : discriminación etaria -niños, jóvenes o adultos mayores-, étnico nacional -pueblos originarios, 
afrodescendientes-, Educación Sexual Integral, discapacidad, personas en situación de pobreza, condición social, diversidad de género, diversidad familiar, migrantes y refugiados, habitantes de pueblos limítrofes en América Latina, ruralidad, discriminación político ideológica, religión, creencia, veteranos de guerra;

- el análisis de prescripciones curriculares y propuestas editoriales desde las monoculturas (Santos, 2018) del saber reconocido, del tiempo lineal, de la naturalización de las diferencias, de la escala dominante y del productivismo capitalista.

- $\quad$ síntesis de propuestas elaboradas por estudiantes -debates acerca de las modalidades de evaluación-, para la enseñanza de conceptos de sus disciplinas (matemática, física, química, inglés, biología, computación), desde problemáticas de casos locales y desde concepciones que discuten capitalismo/patriarcado/colonialismo.

\section{MARCOS LEGALES PARA PRÁCTICAS INFORMADAS}

Las reflexiones y los casos que explicitan la necesidad de analizar las relaciones entre justicia y género y las distintas concepciones de justicia de género resultan muy oportunas en nuestro contexto nacional actual. En particular, poder pensar en justicias desde un feminismo descolonial invita a proyectar qué implica(ría) la justicia y el acceso a la justicia en contextos de pluralismo jurídico.

Rachel Sieder (2018) coordina una colección de estudios, de investigadoras activistas que han participado en diferentes proyectos colectivos y en procesos de organización y de intervención en cuestiones legales de luchas de justicia de género. En ella muestran la necesidad profunda de trabajar por otras concepciones de "(in)justicia" e "(in)seguridad". Queda claro que no se puede hablar de las relaciones entre justicia y género sin referir a privación de acceso a la tierra; falta de experiencia, formación o educación; miedo; dependencia económica de los hombres; violencia física y sexual; abandono, negación sistemática de la participación.

En esas racionalidades se tornan medulares las referencias a:

Violencia de género e interseccionalidad. La violencia de género es un fenómeno complejo y multidimensional que no se puede reducir a la violencia física o interpersonal: es además estructural, simbólico y político (Bourgois, 2001 en Sieder, 2018, p. 13). Mujeres que han soportado discriminación y opresión desde jerarquías de raza, clase, etnicidad, pobreza y género, las tasas más elevadas de analfabetismo e insalubridad, necesitan conseguir derecho igualitario a tierras, a educación, a la intervención en asuntos comunitarios. La interseccionalidad se enfoca en las maneras específicas en cómo estas categorías sociales abstractas se combinan en contextos históricos particulares para producir y naturalizar matrices de dominación, es decir, ofrece una alternativa de explorar las conexiones entre la violencia estructural y las formas interpersonales de violencia y opresión experimentadas por mujeres.,

Legalidades cosmopolitas subalternas. Santos y Rodríguez-Garavito (2005) denominan así a las formas locales y aterrizadas, de resistencia e innovación legal, llevadas a cabo por los más excluidos y marginados del nuevo orden global. Buscan buscan expandir los cánones legales más allá de los derechos individuales, y se centran en 
la importancia de las construcciones no hegemónicas para la movilización política de estrategias de democratización de marcos legales. Resume la importancia de órdenes legales alternativos generados por actores subalternos.

Pluralidades (i)legales, (in)justicia e (in)seguridad.El paisaje legal en América Latina a principios del siglo XXI, expresa Sieder (2018), es de jurisdicciones híbridas y traslapadas, incluye a las autonomías indígenas y al derecho propio, al derecho nacional, al derecho transnacional de derechos humanos y al derecho comercial, todo en coexistencia con otros órdenes regulatorios informales y a menudo altamente coercitivos. Esto plantea desafíos complejos para cualquier análisis de pluralidades legales contemporáneas, más aún en las interseccionalidades con las dinámicas de género. De igual manera, reflexionar, estudiar casos, trabajar, participar en casos de justicia y género, permitiría establecer analogías para plantear relaciones entre justicia, legalidad y pobreza o entre justicia y ecología, entre justicia y etnias/racialidades/comunidades. Esto gravita en nuestra necesidad de conocer las leyes vigentes, preguntarnos a quiénes representan, analizar a qué intereses responden, cuáles fueron las luchas que las impulsaron o no, y en todas las alternativas subalternas que, en estos sentidos abisales, fueron creadas activa y legalmente ausentes.

\section{EL CASO DE LA LEY 26150 PROGRAMA NACIONAL DE EDUCACIÓN SEXUAL INTEGRAL}

Todo nuestro proyecto de trabajo está atravesado por una fuerte mirada en el Programa Nacional de Educación Sexual Integral, norma que establece como propósito primordial la responsabilidad del Estado de hacer válido el derecho de niños, niñas y jóvenes a recibir Educación Sexual Integral (ESI) en todos los establecimientos educativos. Se aprueba en el año 2006, a partir de la Ley de Educación Nacional -LEN 26206- que rige actualmente en todos los niveles educativos de la República Argentina.

Llamamos ESI al espacio sistemático de enseñanza y aprendizaje que promueve saberes y habilidades para la toma de decisiones conscientes y críticas en relación con el cuidado del propio cuerpo, las relaciones interpersonales, el ejercicio de la sexualidad y de los derechos de los niños, las niñas y los jóvenes. (Ley 26150, 2006).

El Estado provincial ha incorporado los contenidos a los diseños curriculares locales y ha advertido la necesidad de acompañar con una propuesta sistematizada de las/os docentes en el aula. Anticipa y sostiene el trabajo nuestra propia convicción de la importancia de que las/os jóvenes aborden estas problemáticas como un ejercicio genuino de sus derechos, que los habilita en su formación, participación y responsabilidad en la toma de decisiones.

Compartimos con las/os estudiantes de profesorado los marcos legales que año a año vamos actualizando que muestran, como mínima expresión, tanta necesidad desatendida en la educación. 

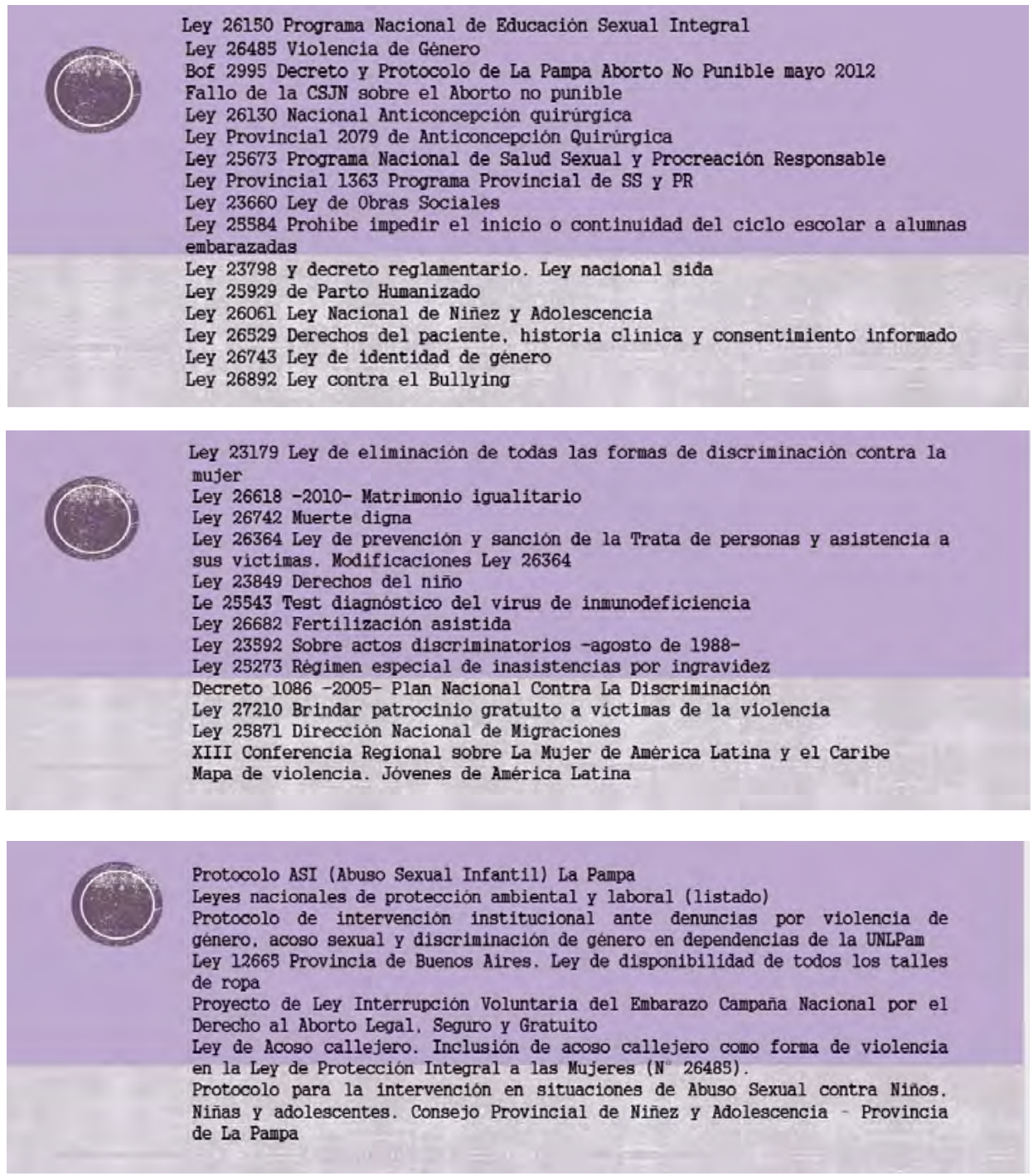

\section{LAS PRODUCCIONES DE LOS/AS ESTUDIANTES, INTERVENCIONES EN UN PROYECTO EDUCATIVO POLÍTICO CURRICULAR}

A modo de cierre, presentamos como resultados de este proceso formación e investigación en campo, las producciones de las/os estudiantes de los profesorados, en las que ponen en juego los fundamentos debatidos y las experiencias desarrolladas en las aulas.

Mencionamos títulos de producciones de las/os estudiantes:

- Explotación sexual de niños, niñas y adolescentes: problemática que no se ve, sociedad que no siente. Cinthia Anahí Tejo y Juan Pablo Gatica

- Educación sexual para poder decidir. La Física desde las unidades de medida relacionadas con la procreación. María Belén Urquiza

- Ladrones de vida. La trata de personas con fines de explotación sexual. Deborah Ramburger y Cielo Viana

- Bullying. Emiliano Camargo 
- En La Pampa de ESI Sí se habla. Acoso sexual en el Colegio Belgrano. Carola Abona y Guardia Brenda

- Embarazo adolescente. Evelyn Esteban. Franco Gómez

- Todos contra el bullying. Leandro Cerani y Ángel Martín

- Identidad virtual. Violencia de género. Luckenich Rocío y González Martín

- Enseñanza Aprendizaje: Un proceso afectado por los problemas de convivencia. El virus como metáfora de la convivencia. Marchisio Luis Santiago y Lecitra Juan

- Vivir plenamente nuestra sexualidad: un derecho de todos y todas. La Sexualidad en personas con discapacidad. Agustina Villarreal y Yohana Marín.

- Reaccionar a tiempo. La física de los accidentes de tránsito. Mauro Bergonzi Rodríguez

- Medicina Alternativa Cannabis. El derecho a la información. Sebastián Romano y Julio Cisneros

- Violencia como problemática escolar. Vidal María y Acosta Santiago

- Con la violencia escolar, ¿qué hacemos? Wenceslao Fernández y Jonathan Balajoch

- Violencia de género. Figueroa Joanna y Rolhaiser Daiana

- Abandono escolar. Violación de los Derechos del niño. Cuando los niños tienen que protegerse de las instituciones que fueron pensadas para protegerlos. Lecitra Milagros y Painemal Daiana

- Las inundaciones como problema político. Laborda Maximiliano

- Diferencias que provocan desigualdades. La Química nos ayuda a interpelar jerarquías Magalì Zappa y Micaela Kollman

- El agua, derecho de todas/os. Pensar la Química desde los "saberes otros". Alejandro Arce, Vanesa Antequera y Evelyn Hidalgo

- La Química de las emociones. Prostitución versus sexualidad placentera. Camila Vicente y Melina Zabaletta

- ¿Cómo construimos modelos y estereotipos? Explicaciones desde la Química. Karen Kollman y Sofía Schaab

- Química, medio ambiente y "saberes otros" resignificación desde las feministas comunitarias. Lía Yanaquén y Juan Kroneberger.

- Distribución y clasificación: igualdad de derechos para ser diferentes. Daniel Capellino y Daiana Soncini

- Deconstruir estereotipos de género en el ámbito escolar. Sepúlveda y Bretón.

- Bullying de Fases. Ana Miranda y Jonathan Sapino

- Del temor al sexo a la sexualidad placentera. Melina Torres y Florencia Rubio

- Interpelar cuentos y canciones tradicionales infantiles; un modo de luchar contra la exclusión. Daniela Rubiano y Tamara Fernández

- Historias de vida (y muerte) que cambiaron la historia. Grooming y Prostitución. Sofía Castillo y Malena Fraga

- La maternidad como mandato femenino. Rocío Martínez y Valentina Molina

- Cyber juegos, adicciones y construcciones de subjetividad. Martín Mauras, Jonathan Lehr y Carolina Reina 
- Recuperando saberes de las doulas, un modo de luchar contra la violencia obstétrica. Solange Cortese y Oriana Ballari

- Deconstrucción de miradas y visiones instauradas en lo social sobre el amor romántico. Andrea Videla y Nicolás Moya

- Tecnologías e identidad de género. El celular en el aula: ¿problema o solución? Lucía Bustamante Meza y Lucrecia Corral

- La mitad sin voz. Discriminación de género en la escuela. Micaela Exner y Eugenia Santos

- El derecho a estar en la escuela y aprender. Exclusión social y educativa. Valverde y Necol.

- Interpelar imágenes y videos, un modo de luchar contra el grooming. Candela Abascal y Jesica Ruiz.

- Autoestima y fracaso escolar en adolescentes de $1^{\circ}$ año de la ESO. Química - Física: la energía y los cambios. Leticia Chiaino y Alina Cortez

- Escolarización de inmigrantes venezolanos en Argentina. Química: los cambios de estado de la materia considerando un caso particular: adolescentes venezolanos en Santa Rosa. Paula Sidabra Andrich y Micaela Alanis

- El abolicionismo como forma de empoderamiento. Abordando miradas abolicionistas desde mujeres argentinas.Micaela Villanueva y Melina Revelino

- La cultura de la alimentación en las aulas: un tipo de violencia institucional. Nutrición y DDHH. Química y Física a través de casos clínicos. Herrero Maeso, Juan Joel y Reyes Maeso Eliana y Vallejos Gabriela

- Redes sociales y violencia. Acciones preventivas frente al Grooming. Jonathan Fussini y Emanuel Metz

- No quiere sentirse valiente, quiere sentirse libre. Acoso callejero. Carolina Corvalán y Carina Cañete

- El teatro nos ayuda para conflictuar Violencias intrafamiliares. Matemática: Información estadística en gráficos.Yanina Lick y Viviana Guittlein

- Hábitos y peligros en la red. Acoso cibernético. Giai Natalia, Victtori Juan y Baudis Nicolás

- Alcoholismo en Adolescentes. Consumo de sustancias tóxicas legales e ilegales. Joaquín Arturo, Francisco Punte

- Feminismos. Derribando mitos. Camila Loza y Julieta Fantini.

- La Segunda Ley de Newton y las Soluciones en un análisis acerca de la explotación sexual. Física: fuerzas y Química: soluciones.Sabetta Funes Florencia y CarassayAmakeik

- El rol de la mujer en el desarrollo de las teorías de reacciones nucleares. Franco Sebastián Suarez y Marcos Andrés VicondoBasilisen

- La naturalización de la violencia. Física: Leyes del movimiento. Gazzano Gabriel

- Videojuegos y sus ideologías. Computación. Matías Gandini y Nicolás Francisco Dasso. Deconstrucción de miradas y visiones instauradas en lo social sobre el amor romántico. Andrea Videla y Nicolás Moya

- No quiere sentirse valiente, quiere sentirse libre. Acoso callejero. Carolina Corvalán y Carina Cañete 
- Vivir plenamente nuestra sexualidad: un derecho de todos y todas. La Sexualidad en personas con discapacidad. Agustina Villarreal y Yohana Marín

- Mirar la diversidad desde la discapacidad en la Escuela de Inclusión № 1 de Santa Rosa. Karen Lubones y Georgina Cluster.

- En La Pampa, de ESI SÍ se habla. Acoso sexual en el Colegio Belgrano. Carola Abona y Guardia Brenda.

- Interpelar imágenes y videos, un modo de luchar contra el grooming. Candela Abascal y Jesica Ruiz.

- Deconstruir estereotipos de género en el ámbito escolar. Sepúlveda y Bretón

- El abolicionismo como forma de empoderamiento. Abordando miradas abolicionistas desde mujeres argentinas. Micaela Villanueva y Melina Revelino.

- Identidades autopercibidas y deconstrucción de masculinidades hegemónicas. Juan Rivas,Francisco Diego y Cristian Yacoppini

- Mirar la diversidad desde la discapacidad en la Escuela de Inclusión № 1 de Santa Rosa. Karen Lubones y Georgina Cluster.

- El rol de la mujer en el desarrollo de las teorías de reacciones nucleares. Franco Sebastián Suarez y Marcos Andrés Vicondo Basilisen

- La cultura de la alimentación en las aulas: un tipo de violencia institucional. Nutrición y DDHH. Química y Física a través de casos clínicos (anorexia, bulimia, obesidad, desnutrición). Herrero Maeso, Juan Joel y Reyes Maeso Eliana y Vallejos Gabriela

- Medios de comunicación, el rating y los rankings en la manipulación y en la banalización de la información. Iván Lucas Burgués y Matías Pereyra

- Estadísticas del patriarcado. Wiliams Noel Uribe

\section{REFLEXIONES FINALES}

Nos propusimos para este trabajo hacer una reconstrucción crítica de la experiencia formativa en el nivel superior a partir de interrogantes iniciales acerca de cuáles son los saberes necesarios para que nuestras prácticas educativas visibilicen personas y acciones ausentes, subalternizadas en la producción de saberes-aportes desde violencia de género e interseccionalidad-

Las producciones finales de las/os estudiantes dan cuenta que hemos podido poner en tensión la herencia recibidadesaprendiendo y reaprendiendo;se valora que se aprende con otrxs. Trabajamos para producir, conocer, recrear lo genuinamente local -aportes desde legalidades cosmopolitas subalternas. Por ello el trabajo para producir saberes se gestan en relación a las escuelas que transitan en las ayudantías, a los afectos que habitan en esos tiempos, las identidades que construyen/fortalecen/ confirman en esa a cultura escolar; a la búsqueda de formas alternativas generadas por movimientos sociales, colectivas, agrupaciones, cooperativas que hayan podido tomar las riendas de sus propias vidas en procesos cogestivos.

Además rescatamos valoraciones en relación a la estrategia político -didáctica de enmarcar las problemáticas sociales con las que se trabaja en un marco legal en el que sostiene la vida comunitaria y ciudadana -aportes desde pluralidades (i)legales, 
(in)justicia e (in)seguridad -En las políticas para el cuidado este marco construye y amplía ciudadanía.

El esfuerzo por descolonizar el curriculum implica conflicto, confrontación, negociaciones y produce algo nuevo -se produce una enorme cantidad de realidad que no existía antes porque se crean nuevos modos de entender-y se convierte en un desafío para las escuelas, educadoras/es, y universidades. 


\section{REFERENCIAS BIBLIOGRÁFICAS}

1.Alonso, G. B. \& Zurbriggen, R. (2014). Transformando corporalidades: desbordes a la normalidad pedagógica. Educar em Revista, 1, pp. 53-69.

2. Apple, M. y Beane, J. (2000). Escuelas democráticas. Madrid: Morata.

3. Araujo Freire, A. M. (ed.) (2007). Pedagogía de la tolerancia. Buenos Aires: Fondo de Cultura Económica-Centro de Cooperación Regional para la Educación de Adultos en América Latina y el Caribe.

4. Connell, R. (1997). Escuelas y justicia social. Madrid: Morata.

5. de Alba, A. (1998). Currículum: Crisis, Mito y Perspectivas. Buenos Aires: Miño y Dávila.

6. Freire, P. (2000). Pedagogía de la indignación. Cartas pedagógicas en un mundo revuelto. Sao Paulo: UNESP

7.Gomes, N. (2012). Relações Étnico-Raciais, Educação e Descolonização dos Currículos, Currículo sem Fronteiras, 12, 1, pp. 98-109.

8. Menesses, M.P. \& Bidaseca, K. (2018). As epistemologias do Sul como expressão de lutas epistemológicas e ontológicas. En Menesses, M.P. \& Bidaseca, K. (coords.) Epistemologías del Sur. pag. 63 -82. Buenos Aires: CLACSO/Coímbra: CES.

9. Rufer, M. (2016). El archivo: de la metáfora extractiva a la ruptura poscolonial. En Menesses, M.P. \& Bidaseca, K. (coords.) Epistemologías del Sur. pag. 85-110. Buenos Aires: CLACSO/ Coímbra: CES

10. Santos, B. de Sousa. (2006) A Gramática do Tempo: para uma nova cultura política. São Paulo: Cortez.

11. Santos, B. de Souza (2009). Una epistemología del sur: la reinvención del conocimiento y la emancipación social. México: Siglo XXI, CLACSO.

12. Santos, B. de Souza (2010). Descolonizar el saber, reinventar el poder. Buenos Aires: Trilce.

13. Santos, B. de Sousa (2018). Introducción a las Epistemologías del Sur. En Menesses, M.P. \& Bidaseca, K.(coords.) Epistemologías del Sur. pag. 25 -62 Buenos Aires: CLACSO/Coímbra: CES.

14. Sieder, R. (coord.). (2018). Exigiendo Justicia y Seguridad. Mujeres Indígenas y pluralidades legales en América Latina. México: Publicaciones Casa Chata.

15. Santos, B de Sousa y Rodríguez Garavito, C. (2007) (editores) El derecho y la globalización desde abajo: Hacia una legalidad cosmopolita. México: Anthropos.

16. Tadeu da Silva, T. (1997) Descolonizar el currículo: estrategias para una pedagogía crítica. En Gentili, P. (comp.) Cultura, política y currículo (ensayos sobre la crisis de la escuela pública). pag. 27-37. Buenos Aires: Editorial Lozada.

17. Torres Santomé, J. (1997). El mundo visto desde las instituciones escolares: la lucha contra la exclusión. Educación, Desarrollo y Participación Democrática. Proyecto y Tú... ¿Cómo lo ves? pp. 77-90.

18. Torres Santomé, J. (2011). Justicia Curricular: El caballo de Troya de la cultura escolar. Madrid: Morata. 